\title{
Impact of clinical pharmacist intervention on diabetes related quality-of-life in an ambulatory care clinic
}

\author{
Douglas L. JENNINGS, Kelly R. RAGUCCI, Elinor CG. CHUMNEY, Andrea M. WESSELL.
}

\begin{abstract}
${ }^{*}$
The purpose of this one-year observational study was to evaluate quality of life in patients at the Medical University of South Carolina Family Medicine clinic who were followed by a clinical pharmacist diabetes educator.

Methods: Patients who have been seen by the clinical pharmacist for diabetes education and management services were contacted by telephone and asked to complete a previously validated Diabetes-related Quality of Life (DRQL) survey. In addition, the patient's most recent hemoglobin A1C, blood pressure, fasting lipid panel and aspirin use were obtained from the electronic medical record. Correlation and logistic regression analysis was completed in order to assess the quality of life score and clinical outcomes.

Results: A total of 47 patients completed the survey (37\%). The median overall score was 1 (1-very satisfied; 5-very dissatisfied). Patients who were more satisfied with their current treatment tended to have lower LDL, systolic and diastolic blood pressure $(B P)$ values $(r=0.32,0.3,0.33 ; p=0.03$, $0.03,0.02)$. In addition, patients taking more medications were more dissatisfied with the amount of time spent managing their disease $(r=0.29$, $p=0.04$ ), felt more pain associated with the treatment of their disease $(r=0.32, p=0.02)$, and were more worried that their body looked different as a result of their diabetes $(r=0.32, p=0.02)$. Conclusion: Patients in this clinic were highly satisfied with their quality of life. The authors found that trends exist for relationships between several important clinical parameters and quality of life.
\end{abstract}

Keywords: Diabetes. Quality of life. Outcome Assessment (Health Care). United States.

\footnotetext{
"Douglas L. JENNINGS, PharmD. Cardiovascular Research Fellow. Eugene Applebaum College of Pharmacy and Health Sciences, Wayne State University, Detroit, MI (USA).

Kelly R. RAGUCCI, PharmD, FCCP, BCPS, CDE. Associate Professor, Pharmacy and Clinical Sciences/Family Medicine. South Carolina College of Pharmacy, Medical University of South Carolina, Charleston, SC (USA).

Elinor C.G. CHUMNEY, PhD, MSc. Assistant Professor, Pharmacy and Clinical Sciences. South Carolina College of Pharmacy, Medical University of South Carolina, Charleston, SC (USA).

Andrea M. WESSELL, PharmD, BCPS, CDE. Assistant Professor, Pharmacy and Clinical Sciences/Family Medicine. South Carolina College of Pharmacy, Medical University of South Carolina, Charleston, SC (USA).
}

\begin{abstract}
RESUMEN
El objetivo de este estudio observacional de un año fue evaluar la calidad de vida en pacientes en la clínica de medicina familiar de la Universidad de Carolina del Sur que eran seguidos por un farmacéutico clínico educador de diabetes. Métodos: Se contactó por teléfono a los pacientes que habían sido vistos por el farmacéutico clínico para su educación en diabetes y la gestión de servicios, y se les pidió que completasen un cuestionario previamente validado del Diabetes.related Quality of Life (DRQL). Además, se obtuvieron de la historia clínica los valores más recientes de hemoglobina A1C, presión arterial, perfil lipídico en ayunas y uso de aspirina. Se realizó un análisis de correlaciones y de regresión logística para evaluar la puntuación de calidad de vida y los resultados clínicos.

Resultados: Un total de 47 pacientes completaron el estudio (37\%). La mediana de la puntuación global fue de 1 (1-muy satisfecho; 5-muy insatisfecho). Los pacientes más satisfechos con su tratamiento actual tendían a tener menores valores de LDL, presión arterial sistólica y diastólica $(\mathrm{r}=0.32,0.3$, $0.33 ; \mathrm{p}=0.03,0.03,0.02$ ). Además, los pacientes que toman más medicamentos estaban más insatisfechos con el tiempo empleado en cuidar de su enfermedad $(r=0.29, p=0.04)$, sentían más dolor asociado al tratamiento de su enfermedad $(r=0.32$, $\mathrm{p}=0.02$ ), y estaban más preocupados de que su cuerpo pareciese diferente por causa de la diabetes $(\mathrm{r}=0.32, \mathrm{p}=0.02)$.

Conclusión: Los pacientes de esta clínica estaban altamente satisfechos con su calidad de vida. Los autores encontraron que existen tendencias de las relaciones entre varios parámetros clínicos importantes y la calidad de vida.
\end{abstract}

Palabras clave: Diabetes. Calidad de vida. Evaluación de resultados en salud. Estados Unidos.

\section{(English)}

\section{INTRODUCTION}

Diabetes is progressive disease that currently afflicts about 20.8 million Americans, or roughly 7 percent of the total population, and its presence is associated with significant adverse clinical, humanistic and economic outcomes. ${ }^{1}$ Diabetes is implicated as the leading cause of blindness, kidney failure, and non-traumatic limb amputations in the United States. ${ }^{1}$ Furthermore, patients with diabetes 
have a 2 to 4 fold increased risk of stroke and death from heart disease, and they frequently experience periodontal disease, sexual dysfunction, and neuropathy. The total economic burden of diabetes in the U.S. in 2002 was estimated to be $\$ 132$ billion, accounting for one out of every ten health care dollars spent that year. ${ }^{1}$

Data from the United Kingdom Prospective Diabetes Study (UKPDS) and Diabetes Control and Complications (DCCT) trial demonstrate that control of hyperglycemia is paramount in minimizing the adverse clinical consequences of patients with diabetes. ${ }^{2,3} \quad$ Pharmacist-administered diabetes education and management services have been shown to improve glycemic control over standard treatment, as well as to improve control of blood pressure and hyperlipidemia and increase the frequency of aspirin use. ${ }^{4-9}$ Morello et al. demonstrated that one-third of patients who received care in a pharmacist managed diabetes care clinic reached goal hemoglobin $\mathrm{A} 1 \mathrm{C}$ and blood pressure values of $<7 \%$ and $<130 / 80$, respectively. ${ }^{5}$ Whereas the national average for uncontrolled diabetes (A1C>9.5 percent) is 36.9 percent, after 1 year of treatment only 3.5 percent of patients treated in this study were uncontrolled. Kiel et al showed similar results, with pharmacist intervention increasing the number of patients with an A1C of $\leq 7 \%$ from 19 to 50 percent. ${ }^{4}$ Patients in this study also had significant increases in the frequency of urinalysis and retinal screenings after pharmacistmanaged care.

While clinical parameters such as glycemic and blood pressure control are key targets for pharmacist intervention, humanistic outcomes (such as symptom status, functional status and quality of life) must also be considered when managing patients with diabetes. ${ }^{10}$ Data from 2005 shows that after adjusting for age, the prevalence of selfreported fair or poor health among adults with diabetes was $46.7 \%$, more than three times the rate among adults without diabetes. ${ }^{11}$ This could be due to many factors, such as patients exhibiting symptoms of uncontrolled disease (e.g., fatigue, polyuria) or complications, the burden of disease management, and the social stigma associated with diabetes.

Results on the impact of a pharmacist's intervention on humanistic outcomes in patients with diabetes have been discordant. Scott et al. demonstrated that patients enrolled in a pharmacist-managed diabetes care program had improved scores on the diabetes quality of life questionnaire over a 9-month period when compared to patients in a control group without pharmacist intervention. ${ }^{6}$ Patients who received pharmaceutical care were more satisfied with their care, had less worry about their disease, and had a higher perceived health level. Baran et al. showed that 6 months of diabetes-specific counseling in 88 patients improved 3 of 8 quality of life domains as measured by the Short Form 20 $(S F-20){ }^{12}$ Jaber et al. evaluated 39 African American patients with diabetes over a 4-month period who were being treated at a pharmacistmanaged outpatient clinic. ${ }^{13}$ Quality of life as measured with the Health Status Questionnaire was not different within or between the groups who received pharmacist intervention and those who did not. Finally, data from the Asheville Project revealed that a community pharmacy diabetes care program did not result in statistically significant improvements in functional status as measured by the Short Form 12 (SF-12). ${ }^{14}$ It is important to note that humanistic outcomes were a secondary outcome in all of the above mentioned studies, and therefore type II error could explain the lack of benefit seen in some of the results as the studies likely were not powered to show a difference in secondary outcomes. Also, most of the instruments in these studies measure health status rather than quality of life. Therefore, data primarily assessing pharmacist intervention on quality of life are lacking.

The primary purpose of this observational study is to evaluate the effectiveness of pharmacistadministered diabetes management services on diabetes-related quality of life in an ambulatory family medicine clinic. Clinical outcome measures of $\mathrm{A} 1 \mathrm{C}$, blood pressure, lipid values, and aspirin use, were also collected to determine if a correlation exists between quality of life and these variables.

\section{METHODS}

\section{Setting}

The Medical University of South Carolina Family Medicine Center is a multidisciplinary health care site consisting of attending physicians, pharmacists, mid-level providers, and nursing staff. Pharmacists, pharmacy residents and pharmacy students provide diabetes education and management services to patients in a physician referral, appointment-based environment. These comprehensive services are conducted in accordance with the American Diabetes Association National Standards. ${ }^{15}$ The pharmacists providing these services have credentials as certified diabetes educators and practice under a standardized protocol. Physicians refer patients to the pharmacist for additional care in response to several triggers, such as poor glycemic control, lack of understanding of their disease, or difficulty in self-monitoring of glucose or insulin administration.

Prior to the first visit, the pharmacist extracts pertinent information from the patient's electronic medical record, such as past medical and social history, current medications, and laboratory data. On the initial visit, the pharmacist gathers further information from the patient regarding diet, exercise, and immunizations. The pharmacist then provides patient-specific education, devises a comprehensive set of individualized goals (with clear outcomes and timelines), orders laboratory tests as needed, and provides a glucometer if the patient does not already have one. When necessary, clinical pharmacists adjust drug regimens in accordance with the protocol. Examples include increasing a patient's atorvastatin dose from $20 \mathrm{mg}$ to $40 \mathrm{mg}$ for additional low density lipoprotein (LDL) reduction or decreasing an evening insulin dose in a patient with morning hypoglycemia. Pharmacists consult with 
the patient's primary care provider before initiating or discontinuing medications. Depending on the patient, dietary counseling can become increasingly complex, such as moving from discussing the "plate method" to carbohydrate counting. Goals are reassessed at each visit and detailed progress notes are entered into the patient's electronic medical record. Patients are scheduled for subsequent visits with the pharmacist based on their specific goals and needs. In addition, all patients are followed up at visits with the primary care physician.

\section{Data Collection}

All patients 18 years or older who had at least one visit with a clinical pharmacist diabetes educator between July 2005 to July 2006 were eligible for inclusion into this study. The primary outcome was the score on our diabetes-related quality of life questionnaire, which is a modified version of a previously validated quality of life instrument. ${ }^{16}$ Modifications to the survey were minor, and were restricted to deletion of several duplicate items to streamline the survey for phone administration. The final version contained a total of 32 questions, and it was divided into satisfaction, impact and worry subsections. For the satisfaction subsection, patients ranked their satisfaction with each item on a 5-point Likert scale, with answers ranging from 1 to 5 (very satisfied to very dissatisfied, respectively). On the impact and worry subsections, patients were asked to quantify how often they felt diabetes impacted their quality of life or worried about their diabetes. Their responses again were ranked on a 5-point scale ranging from 1 (never) to 5 (always) for each question. Median scores were assessed for each subsection and for the entire survey overall.

Patients were contacted via telephone and asked to complete the survey, and all patients were given a verbal waiver of informed consent. Secondary outcomes include correlations between quality of life and clinical parameters of A1C, blood pressure, cholesterol, and aspirin use. These clinical values were extracted from the patient's electronic medical record.

The principle investigator was responsible for administering all of the surveys. A written script was utilized for each phone call to help minimize variability and interviewer bias. Patients were excluded after three attempts to reach them on three separate dates and times. Patients were also excluded if they elected not to complete the survey or if they were unable to answer the questions due to mental impairment, which was at the discretion of the principal investigator.

\section{Statistics}

All data was entered into a Mircosoft Excel ${ }^{\mathrm{TM}}$ (Microsoft, Redmond, WA) database and analyzed using StataTM Version 8.0 statistical software (Stata Corporation, College Station, TX). Descriptive statistics were used to analyze the primary outcome and baseline clinical values, with medians reported for the ordinal survey (quality of life) data and means and standard deviation reported for the continuous clinical and demographic data. Correlation statistics were used to examine relationships between quality of life and clinical outcomes. Selected relationships with statistically significant unadjusted correlation statistics $(p \leq 0.05)$ were further analyzed using logistic regression analysis to adjust for age and gender as potential confounders. The Institutional Review Board approved this study for Research with Human Subjects at the Medical University of South Carolina.

\section{RESULTS}

A total of 105 patients were initially eligible for inclusion. After a reasonable attempt was made to contact these patients, 58 were excluded, leaving 47 completed surveys. The most common reasons for exclusion were failure to reach after three attempts (43\%), disconnected phone lines (19\%), and inability to complete survey due to mental impairment (7\%).

Baseline characteristics are reported in Table 1 . Patients were mostly middle-aged females with type 2 diabetes mellitus. The average hemoglobin A1C was 7.6 percent, with 47 percent of patients achieving a goal $\mathrm{A} 1 \mathrm{C}$ of less than 7 percent. Most patients in the present study had seen a clinical pharmacist more than once, with the average number of visits during the one year study period exceeding five.

\begin{tabular}{|c|c|}
\hline \multicolumn{2}{|l|}{ Demographics } \\
\hline Age (SD) & 58 years $(12)$ \\
\hline Female & $74 \%$ \\
\hline Type 2 Diabetes Mellitus & $98 \%$ \\
\hline \multicolumn{2}{|c|}{ Clinical and Service Measurements (SD) } \\
\hline Hemoglobin A1C & $7.6 \%(1.7)$ \\
\hline Systolic Blood Pressure & $142 \mathrm{mmHg}(25.8)$ \\
\hline Diastolic Blood Pressure & $75 \mathrm{mmHg}(13.1)$ \\
\hline Low Density Lipoprotein & $98(32)$ \\
\hline High Density Lipoprotein & $47 \mathrm{mg} / \mathrm{dl}(17.8)$ \\
\hline Triglycerides & $134 \mathrm{mg} / \mathrm{dl}(91)$ \\
\hline Total Cholesterol & $170 \mathrm{mg} / \mathrm{dl}(38)$ \\
\hline Number of Medications & $1.7(0.75)$ \\
\hline Duration of Diabetes & 5.6 years $(4.8)$ \\
\hline $\begin{array}{l}\text { Total Number of Visits with } \\
\text { Pharmacist }\end{array}$ & $5.36(4.5)$ \\
\hline \multicolumn{2}{|c|}{ Percent of Patients at Goal for Clinical Outcomes } \\
\hline Documented Aspirin Use & $66 \%$ \\
\hline Hemoglobin A1C $<7$ percent & $47 \%$ \\
\hline Blood Pressure of $<130 / 80 \mathrm{mmHg}$ & $34 \%$ \\
\hline Low Density Lipoprotein $<100$ mg/dl & $60 \%$ \\
\hline
\end{tabular}

Diabetes related quality of life as measured by the questionnaire was excellent, with a median overall score of 1 (very satisfied). On the satisfaction subsection, patients also reported a median score of 1 , which means that most patients were very satisfied with the symptoms of their disease. On the impact subsection, the median score was 2 , which indicates that most patients rarely felt adverse effects that they attributed to their diabetes. Finally, on the worry subsection, patients reported a median score of 1 , which suggests that most patients rarely worried about their diabetes. 
At an item level, there were several unadjusted correlations between quality of life and various clinical outcomes. For example, patients more satisfied with their current treatment tended to have lower LDL, systolic and diastolic blood pressure $(B P)$ values $(r=0.32,0.3,0.33 ; p=0.03,0.03,0.02)$ Men tended to be more satisfied with the amount of time spent managing their diabetes $(r=-0.326$, $p=0.02$ ), whereas older patients tended to be more dissatisfied with amount of time spent getting checkups ( $r=-0.31, p=0.03$ ). Finally, patients taking more medications were more dissatisfied with the amount of time spent managing their disease $(r=0.29, p=0.04)$, felt more pain associated with the treatment of their disease $(r=0.32, p=0.02)$, and were more worried that their body looked different as a result of their diabetes $(r=0.32, p=0.02)$.

After adjusting for the potential confounders of age and gender with logistic regression analysis, only the number of medications was found to be a statistically significant predictor of these survey responses. Patients taking more medications were still more dissatisfied with the amount of time spent managing their disease, felt more pain associated with their treatment and were more worried about the appearance of their body $(p=0.05,0.02$, and 0.02).

\section{DISCUSSION}

The results of our study demonstrate that patients seen by clinical pharmacist diabetes educators report an overall excellent diabetes related quality of life. Patients were satisfied with their treatment, felt little impact from their disease and rarely worried about negative consequences from their diabetes. Furthermore, several clinical parameters correlated well with quality of life, most notably the number of medications that the patient took to manage their disease. To the best of our knowledge, this is the first published study examining quality of life as the primary outcome in patients with diabetes receiving care from pharmacists, and it is the first study to attempt to correlate clinical and humanistic outcomes in these patients.

Humanistic outcomes in patients with diabetes frequently suffer as a result of their disease. These patients have consistently reported lower scores on the Short Form-36 compared to both healthy patients and those with other chronic diseases. ${ }^{17}$ As stated previously, prevalence of self-reported fair or poor health among adults with diabetes is more than three times the rate among adults without diabetes. ${ }^{11}$ In order to compare this national data to the present study, patients who reported a median overall score of 3,4 or 5 (neutral, somewhat dissatisfied or very dissatisfied with their overall quality of life, respectively) were considered to have reported fair or poor quality of life. Of the 47 patients surveyed, $17 \%$ reported fair or poor quality of life by this definition, which is significantly better than the national average and is almost at the level of patients without diabetes.

Several interesting correlations were found between clinical parameters and quality of life outcomes. In both the unadjusted and adjusted analysis, increasing number of medications negatively impacted several quality of life domains. Patients taking more medications were less satisfied with the amount of time spent managing their disease, felt more pain associated with their diabetes treatment and were more worried that their body looked differently as a result of their diabetes. These results are not unexpected as patients requiring more medications are likely to have increased severity of disease and may be more likely to require treatment with insulin. Insulin requires daily injections and frequent monitoring of blood glucose and is associated with weight gain, all of which would translate into more time spent managing the disease, more pain, and possible deterioration in physical appearance. These results indicate a need for health care providers who manage diabetes to pay particular attention to the quality of life of patients who take multiple medications.

A simple correlation analysis showed that patients who were more satisfied with their current treatment tended to have better LDL and BP values. The disappearance of this association after the logistic regression analysis can likely be attributed to the high degree with which each of these variables is correlated to each other, which means that patients with lower LDL also tended to have lower BP values. When $\mathrm{A} 1 \mathrm{C}$ was added to this analysis, it also correlated well with the other variables like LDL and BP, which suggests that a patient's A1C is also an important predictor of how satisfied patients are with their current treatment.

Our study is subject to possible limitations. The sample size of 47 patients is relatively small. Recall bias is possible with any survey; however, as our survey was asking respondents about their current state of mind rather than about past experiences, this type of bias is less likely. Selection bias is also possible, as patients with strong opinions (either good or bad) are more likely to complete a survey than those who are indifferent. In an effort to minimize selection bias, all patients seen by clinical pharmacist diabetes educators during the study period were contacted an equal number of times and given an equal opportunity to complete the survey. At first glace, the baseline A1C of 7.6 percent may indicate selection bias in favor of healthier patients, however the results of a previous study at our clinic showed that patients who received approximately one year of pharmacist intervention achieved an $\mathrm{A} 1 \mathrm{C}$ value of 7.8 percent. $^{7}$ This strong similarity suggests that these patients adequately represent the diabetes population seen by clinical pharmacist diabetes educators at our clinic. In addition to selection bias, interviewer bias is also possible, as all surveys were administered by the principal investigator. Furthermore, as the survey was only administered at one time point, it is not possible to determine if patient's quality of life improved over time as a result of the care provided by pharmacists. Finally, by design as a quality assurance project, we did not include a control group and comparisons cannot be drawn between the quality of life of patients seen by clinical 
pharmacists and those who received standard medical care.

\section{CONCLUSIONS}

This one-year study demonstrates that most patients being followed by clinical pharmacist diabetes educators reported an excellent quality of life. However, patients taking more medications tended to report lower quality of life on several items. This hypothesis generating data could be used to design interventions to study the impact of pharmaceutical care on the quality of life of patients with diabetes over time, with a secondary emphasis of delineating further relationships between clinical and humanistic outcomes.

\section{ACKNOWLEDGMENTS}

The authors would like to acknowledge the team of pharmacists from this practice site, Sarah Shrader, PharmD, BCPS and Amy Thompson, PharmD. We would also like to acknowledge the contributions to patient care provided by SCCP-MUSC campus pharmacy students and residents.

\section{CONFLICT OF INTEREST}

None declared.

\section{References}

1. American Diabetes Association. Diabetes Statistics. URL http://www.diabetes.org/diabetes-statistics.jsp (accessed December 27, 2006).

2. Diabetes Control and Complications Trial Research Group. The effect of intensive treatment of diabetes on the development and progression of long-term complications in insulin-dependent diabetes mellitus. N Eng J Med 1993;329:977-86.

3. UK Prospective Diabetes Study Group. Intensive blood-glucose control with sulfonyureas or insulin compared with conventional treatment and risk of complications in patients with type 2 diabetes (UKPDS 33). Lancet 1998;352:837-53.

4. Keil PJ, McCord AD. Pharmacist impact on clinical outcomes in a diabetes disease management program via collaborative practice. Ann Pharmacother 2005;39:1828-32.

5. Morello CM, Zadvorny EB, Cording MA, Suemoto RT, Skog J, Harari A. Development and clinical outcomes of pharmacist-managed diabetes care clinics. Am J Health-Syst Pharm 2006;63:1325-31.

6. Scott DM, Boyd ST, Stephan M, Augustine SC, Reardon TP. Outcomes of pharmacist-managed diabetes care services in a community health center. Am J Health-Syst Pharm 2006;63:2116-22.

7. Ragucci KR, Fermo JD, Wessell AM, Chumney CG. Effectiveness of Pharmacist-Administered Diabetes Mellitis Education and Management Services. Pharmacotherapy 2005;25:1809-1816.

8. Cranor CW, Bunting BA, Christensen DB. The Ashville Project: Long-term Clinical and Economic Outcomes of a Community Pharmacy Diabetes Care Program. J Am Pharm Assoc 2003; 43:173.

9. Lial S, Glover JJ, Herrier RN, Felix A. Improving quality of care in diabetes through a comprehensive pharmacist-based disease management program. Diabetes Care 2004;27(12):2983-84.

10. The DCCT Research Group. Influence of intensive diabetes treatment on Quality-of-Life outcomes in the Diabetes Control and Complications Trial. Diabetes 1996;19:195-202.

11. Centers for Disease Control and Prevention. Self-rated fair or poor health among adults with diabetes--United States, 1996-2005. MMWR Morb Mortal Wkly Rep 2006;55(45):1224-7.

12. Baran RW, Crumlish K, Patterson H, Shaw J, Erwin WG, Wylie JD, Duong P. Improving outcomes of communitydwelling older patients with diabetes through pharmacist counseling. Am J Health-Syst Pharm 1999;56:1535-9.

13. Jaber LA, Halapy H, Fernet M, Tummalapalli S, Diwakaran H. Evaluation of a pharmaceutical care model on diabetes management. Ann Pharmacother 1996;30:238-43.

14. Cranor CW, Christensen DB. The Ashville Project: Short-term outcomes of a community pharmacy diabetes care program. J Am Pharm Assoc 2003;43:149-59.

15. Standards of Medical Care in Diabetes. Diabetes Care 2007 30: S4-41.

16. The DCCT Research Group. Reliability and validity of a diabetes Quality-of-Life measure for the Diabetes Control and Complications Trial (DCCT). Diabetes Care 1988; 11:725-31.

17. Luscombe FA. Health-related quality of life measurement in type 2 diabetes. Value Health 2000;3(supp1):S15-28. 